\title{
A Teoria do fato jurídico de Pontes de Miranda em face do pragmatismo analítico de Wittgenstein
}

Pontes de Miranda's theory of juridical fact in view of Wittgenstein's analytical pragmatism

\author{
Antonio Wilker dos Santos \\ Universidade Candido Mendes, UCAM, Brasil \\ Faculdade Unyleya, UNYLEYA
}

Resumo A teoria do fato jurídico, inaugurada por Pontes de Miranda, possui bastante prestígio nos âmbitos do direito civil e processual civil, porém, pouco se questiona a respeito de seus preceitos claramente construídos sob a concepção unívoca de linguagem adotada pelo neopositivismo ou sua relevância para a atualidade. $\mathrm{O}$ caráter dogmático da referida doutrina torna-se patente por meio da noção de incidência infalível da norma jurídica. Este estudo tem por objetivo apresentar argumentos, com supedâneo na filosofia analítico-pragmática do segundo Wittgenstein, ${ }^{1}$ que demonstrem o equívoco do representacionalismo linguístico neopositivista, assim como de uma visão dogmática do Direito. Com relação à metodologia, utilizou-se pesquisa explicativa, abordagem qualitativa, e coleta de dados bibliográfica. Ao final, aponta-se a impossibilidade de uma incidência determinista da norma jurídica que não considera os estudos mais recentes acerca da linguagem.

Palavras-chave: Linguagem; Incidência; Dogmatismo; Neopositivismo; Pragmatismo.

Termo tradicionalmente usado para referir-se à segunda fase da filosofia de Wittgenstein, enquanto a expressão "primeiro Wittgenstein" alude ao que foi escrito no Tractatus Logico-philosophicus (sua primeira obra publicada). 


\begin{abstract}
The theory of legal fact, inaugurated by Pontes de Miranda, has considerable prestige in the areas of civil and civil procedural law, but little is questioned about its clearly constructed precepts under the univocal conception of language adopted by neopositivism or its relevance for the present. The dogmatic character of this doctrine becomes evident through the notion of infallible incidence of the legal norm. The purpose of this study is to present arguments, based on Wittgenstein's analytical-pragmatic philosophy, that demonstrate the misunderstanding of neopositivist linguistic representationalism, as well, as a dogmatic view of law. Regarding the methodology, explanatory research, qualitative approach, and bibliographic data collection were used. In the end, it is pointed out that it is impossible to have a deterministic incidence of the legal norm that does not consider the most recent studies on language.
\end{abstract}

Key-words: Language; Incidence; Dogmatism; Neopositivism; PragMATISM.

\title{
INTRODUÇÃO
}

O pensamento de Pontes de Miranda - exceto em seus últimos trabalhos, quando se encontrava em idade avançada - está em consonância com o desenvolvimento científico de sua época. Como correligionário do positivismo, pertenceu à primeira feição desse movimento - o positivismo sociológico - e ao seu desdobramento voltado a aspectos linguísticos e logísticos - o neopositivismo ou positivismo lógico -, de maneira que sua obra é dividida por seus comentaristas de acordo com tais enquadramentos.

Em sua primeira fase, tipicamente cientificista, o Direito é descrito como processo de adaptação social que pode ser estudado, assim como a sociologia, pelo mesmo método das ciências naturais, sendo possível chegar a um conhecimento verdadeiro e sistematizável tendente à unificação das ciências e à reorganização social (PONTES DE MIRANDA, 1983). Na fase neopositivista, desenvolve a teoria do fato jurídico, exibida no Tratado de Direito Privado, que tem seu aspecto dogmático 
patenteado, principalmente, pela ideia de incidência infalivel da norma jurídica, aspecto dependente da possibilidade de verdades absolutas sobre os fatos.

O movimento neopositivista recebeu influência decisiva da primeira fase da filosofia analítica da linguagem (giro linguístico), da qual o primeiro Wittgenstein, com o Tractatus Logico-philosophicus, foi um dos principais representantes, com Gottlob Frege e Bertrand Russel. Os integrantes dessa tradição filosófica acreditavam que a linguagem possuiria uma única essência, a de representar estados de coisas, e que os problemas da filosofia estariam ligados à má compreensão dessa lógica pictórica. Os preceitos da teoria ponteana estão em perfeita harmonia com tal concepção da linguagem.

Em um segundo momento, a filosofia analítica evoluiu para o que veio a ser denominado de giro linguístico-pragmático, que ocorreu com a chamada filosofia da linguagem ordinária, tendo como principal centro de desenvolvimento a universidade de Oxford, e como maiores representantes Gilbert Ryle e John L. Austin. Mas o pioneirismo nessa área de debate esteve com o próprio Wittgenstein que, após rever sua postura sobre a linguagem, abandonou aspectos empírico-dogmáticos de seu pensamento e se voltou para uma perspectiva pragmática (ANTISERI; REALE, 2006a). Na principal obra dessa fase, Investigações Filosóficas, o mestre austríaco, entre muitas outras retratações em relação ao que foi escrito no Tractatus, desiste da ideia de que a linguagem possui uma única lógica subjacente e passa a perceber seu aspecto puramente contextual, concernente ao uso nas atividades humanas às quais está interligada.

Apoiando-se na evidência de que um dos próprios idealizadores do representacionalismo da linguagem, eloquentemente, comprovou seu equívoco, pretende-se expor a insustentabilidade de uma incidência infalível da norma jurídica completamente construída sob a convicção da monossemia das proposições linguísticas. 


\section{Posturas filosóficas em RelaÇão À POSSIBILIDAde do CO- NHECIMENTO}

Posto que a doutrina de Pontes de Miranda rende-se ao dogmatismo, enquanto a filosofia do segundo Wittgenstein opta pelo pragmatismo (espécie de relativismo), convém destacar as significações de tais terminologias, a fim de que se possa familiarizar-se com o contexto de sua aplicação na epistemologia.

Dogmatismo, ceticismo e relativismo são expressões utilizadas para se referir às atitudes de investigação das doutrinas filosóficas quanto à possibilidade do conhecimento. De forma sucinta, pode-se dizer que a primeira crê que existam verdades absolutas esperando ser desvendadas; a segunda que não se pode atingir certeza alguma, devendo-se perpetuar em estado de dúvida; e a terceira nega o caráter absoluto da verdade, mas afirma uma certeza parcial, compatibilizando os demais aspectos do conhecimento à perspectiva do observador.

Pode-se definir dogmatismo como toda corrente de pensamento que afirma a "possibilidade de conhecer verdades universais quanto ao ser, à existência e à conduta, transcendendo o campo das puras relações fenomenais e sem limites impostos a priori à razão" (REALE, 2002, p. 158). O dogmatismo pode ser parcial ou total. Este ocorre quando se acredita que não há barreiras para o conhecimento, tanto no plano da especulação, quanto no da vida prática; aquele provém da constatação de que alguns autores acreditam em verdades absolutas apenas no campo prático (dogmatismo ético), enquanto outros somente na área teórica (dogmatismo teorético). Por esse motivo, é possível ser dogmático em um sentido, e relativista ou até mesmo cético em outro.

A postura filosófica relativista quanto ao conhecimento afasta de suas especulações a esfera do absoluto, tendo alguma semelhança com o ceticismo, mas deste diferenciando-se por afirmar a possibilidade de um conhecimento que, embora parcial, estaria expurgado de dúvidas. Conforme a classificação feita por Miguel Reale (2002), o pragmatismo é um tipo de relativismo, visto que não se ampara na eventualidade de algo absoluto. O pragmático prende-se a verdades contextuais 
- o conhecimento é relativo ao contexto. A grande diferença entre uma investigação dogmática e outra pragmática é que a primeira acredita piamente que exista algum aspecto cognoscível do absoluto, e estrutura suas teses a partir deste princípio (dogma); enquanto a segunda exclui qualquer possibilidade de conhecer algo de maneira plena. $\mathrm{O}$ relativismo criticista - presente, por exemplo, na doutrina de Hans Kelsen, jurista austríaco - e o pragmático distinguem-se, por sua vez, porque este rompe com a dicotomia sujeito-objeto que aquele mantém. No pragmatismo, observa-se outra forma de enfrentar os problemas filosóficos. Isso constitui uma inovação irrecusável para a teoria do conhecimento, que, finalmente, distancia-se da abordagem que dominou a filosofia desde Descartes, passou pelo criticismo de Kant, e chegou à contemporaneidade. A verdade é teórico-prática, a teoria insere-se como momento da ação ou da vida prática, não se encontra apenas no plano da especulação, mas está necessariamente ligada às formas de vida humanas (WITTGENSTEIN, 1999). O conhecimento está condicionado à cultura, à civilização e à natureza humana.

\section{O dogmatismo de Pontes De Miranda}

Há, historicamente, uma associação da decisão judicial com a pretensão de alcançar-se um resultado justo, verdadeiro ou correto. Devido a tal mentalidade idealista, que costuma hipostasiar a verdade e a justiça, e que ainda predomina no senso comum contemporâneo, as teorias de cunho dogmático encontram bastante respaldo. Isto pode ser constatado pelo grande prestígio que continua a apresentar a teoria do fato jurídico, principalmente nos âmbitos do direito civil e processual civil. Porém, pouco se comenta sobre suas características patentemente neopositivistas, e ainda menos a respeito de sua atualidade.

Pontes de Miranda, ao contrário de outros dogmáticos, buscou o rigor de definições e conceitos em uma tentativa de teorização do direito por uma abordagem descritiva da realidade, "razão pela qual a sua teoria foi chamada de naturalismo jurídico" (KRELL, 2010, p. 75). Torquato Castro (2009, p. 38) alega que "poucos juristas talvez 
tenham estado tão perto da ciência em sentido literal quanto Francisco Cavalcanti Pontes de Miranda". De fato, os ideais neopositivistas não poderiam ter sido melhor absorvidos por uma teoria do direito do que foram na doutrina ponteana.

Convém lembrar que não se deve confundir dogmática jurídicaque se qualifica pelo fato de ter como ponto de partida necessário, na construção das teorias positivistas, as normas jurídicas - com teoria do direito de caráter dogmático. Afinal, a postura dogmática quanto ao conhecimento apresenta-se no mundo jurídico de outras maneiras, como em algumas vertentes de jusnaturalismo ou de direito natural. Pertence ao dogmatismo, desse modo, toda doutrina filosófica, jurídica ou não, que, com relação à possibilidade do conhecimento, afirma sempre certo aspecto do absoluto como cognoscível (REALE, 2002). Já a dogmática jurídica caracteriza-se por uma abordagem metódica tendente a tratar o Direito por um viés referente à forma (formalismo), e não ao conteúdo, numa postura tipicamente reducionista, onde aquilo que não se pode pôr em questionamento é o Direito Positivo como conjunto das normas jurídicas vigentes.

O conjunto da obra de Pontes de Miranda apresenta-se, sob um ponto de vista epistemológico, como uma teoria de caráter dogmáti$c o$, mas apenas sua segunda fase classifica-se como dogmática jurídica. Nesse período, evidencia-se o entendimento de que a norma jurídica possui uma única interpretação correta, que ocorre em função da univocidade nas expressões empregadas nos enunciados normativos. É justamente tal característica que permite a tentativa de elucidação do fenômeno jurídico pela descrição de sua forma, sem se importar com o conteúdo.

A teoria do fato jurídico consiste, fundamentalmente, em distinguir o que é jurídico daquilo que não é (fatos ajurídicos). Para Pontes de Miranda (2012, p. 65), o mundo constitui-se de fatos, a totalidade dos fatos é o mundo; e neste mundo dos fatos, que consiste em toda a realidade, há um subconjunto - o mundo jurídico -, assim, "os fatos do mundo ou interessam ao direito, ou não interessam. Se interessam, entram no subconjunto do mundo a que se chama mundo jurídico e se 
tornam fatos jurídicos; pela incidência das regras jurídicas, que assim os assinalam".

$\mathrm{Na}$ teoria ponteana, o direito executa a esquematização do mundo físico para fazê-lo jurídico, delimitando precisamente aquilo que é relevante. As regras jurídicas, que se compõem de suportes fáticos, são responsáveis pela criação do mundo jurídico. O suporte fático é, ao mesmo tempo, aquilo que a regra jurídica prevê e sobre o qual ela incide. Quando o fato (simples) ou o conjunto de fatos (fatos complexos) previsto pela regra jurídica (suporte fático abstrato) ocorre (suporte fático concreto) tem-se a incidência - que corresponde à eficácia legal ou eficácia da regra jurídica. Da incidência resulta a juridicização do suporte fático, tornando-o fato jurídico. Assim, os elementos do suporte fático são pressupostos do fato jurídico, e apenas deste pode haver a irradiação de efeitos referentes à eficácia jurídica, segundo os critérios que as próprias regras jurídicas estabeleçam (PONTES DE MIRANDA, 2012).

O suporte fático precisa ser suficiente para que a regra jurídica incida. Assim, "é preciso que todo o suporte fáctico necessário exista" (PONTES DE MIRANDA, 2012, p. 84), ou seja, é imprescindível que todos os fatos essenciais à incidência ocorram. Mas apesar da insuficiência na formação do suporte fático impedir o surgimento do fato jurídico, se ocorrem mais fatos que os previstos, essa excessividade na formação do suporte fático não evita a incidência. Dessa forma, "a incidência é, assim, o efeito da norma jurídica de transformar em fato jurídico a parte do seu suporte fático que o direito considerou relevante para ingressar no mundo jurídico" (MELLO, 2010, p. 77).

Ao distinguir leis naturais de leis jurídicas (em sentido amplo de regras jurídicas), Pontes de Miranda (2012, p. 68, 95) aponta a necessidade da "cisão lógica e política "incidência-aplicação", visto que, de modo diferente das primeiras, as leis jurídicas não coincidem com os fatos, mas, por serem feitas pelo homem, incidem neles. Dessa forma, já que a regra jurídica é artificial, consistindo em processo de adaptação social, não é possível a regra jurídica de concretização simplesmente mecânica, pois "se ela coincidisse com os fatos, não precisaria de 
eventual aplicação". Porém, "a vontade humana nada pode contra a incidência da regra jurídica, uma vez que ela se passa em plano do pensamento". Isto significa que o instituto pertence aos domínios da Lógica. Assim, incidência é uma associação lógica que ocorre por se presumir que uma regra jurídica automaticamente se aplica a um caso nela previsto. Em outras palavras, a coexistência dos suportes fáticos abstrato e concreto resulta em um determinismo lógico que torna inevitável a incidência.

Segundo Pontes de Miranda (2012, p. 74), "a falta no atendimento é que provoca a não-coincidência entre incidência e atendimento (= auto-aplicação) e a necessidade de aplicação pelo Estado". O atendimento é a adesão espontânea das pessoas às regras jurídicas. De acordo com Norberto Bobbio (2008, p. 163), trata-se da obediência não por se temer as possíveis consequências desagradáveis de uma possível violação, "mas por consenso, ou convenção, ou mero hábito, de qualquer forma, por motivos que não pressupõem a possível movimentação do mecanismo da sanção".

A aplicação, por sua vez, "nada é mais do que a declaração da incidência, donde a necessária anterioridade do fato de incidir" (PONTES DE MIRANDA, 1970, p. 42). Em virtude de sua infalibilidade, a incidência deve ser declarada quando ocorrer a aplicação da norma pelo Estado. Contudo, podem ocorrer equívocos na aplicação das regras jurídicas, quando, então, não haverá equivalência entre incidência e aplicação - "aplicação injusta" (PONTES DE MIRANDA, 2012, p. 76). Disso pode-se concluir que a incidência seria a única solução correta de cada caso concreto.

No que se refere à interpretação das regras jurídicas, Pontes de Miranda (2012, p. 13) afirma que "para que se saiba qual a regra jurídica que incidiu, que incide, ou que incidirá, é preciso que se saiba o que é que se diz nela". Daí uma vez que se entenda o sentido da norma, em abstrato, será possível determinar sua aplicação sempre que ocorrer o suporte fático concreto correspondente. Assim, os fatos não carecem de interpretação. Na visão ponteana, interpretar é revelar as normas que compõem o sistema jurídico. 
Depreende-se do exposto que, na teoria do fato jurídico, em virtude da caracterização lógica do fenômeno da incidência, as regras jurídicas possuem força própria para incidir sobre os fatos, independentemente de interferência humana. Incidência, atendimento e aplicação são coisas diferentes e independentes entre si. A incidência da regra jurídica não falha, o que pode falhar é o atendimento e a aplicação. Por conseguinte, a interpretação não pode recair sobre a incidência, mas tem a finalidade de descobrir qual a aplicação correta da regra jurídica, correspondente à verdade (incidência).

\section{Pontes de Miranda e o neopositivismo}

O movimento neopositivista teve início na Áustria, em 1924, quando Herbert Feigl e Friedrich Waismann propuseram a Moritz Schlick a formação de um grupo de discussão, passando a ocorrer os colóquios das sextas-feiras à noite, o que resultou na formação do Círculo de Viena (ANTISERI; REALE, 2006b). Com o tempo, o grupo tornou-se mais organizado, desenvolveu um programa de pesquisa $\mathrm{e}$ criou um periódico (Erkenntnis) para a publicação dos resultados alcançados. Tem-se como representantes desse movimento, além de Moritz Schlick, Rudolf Carnap, Hans Hahn, Otto Neurath, Hans Reichenbach, entre outros. O grupo manteve seus encontros por mais de dez anos, desfazendo-se após seus membros terem sido obrigados ao exílio diante da ameaça crescente do regime nazista alemão (GRAYLING, 2002).

Em A Concepção Científica do Mundo, manifesto que explicitou o programa de pesquisa neopositivista, foram estabelecidos como objetivos: a) o desenvolvimento de uma ciência unificada; b) a busca de um simbolismo livre das impurezas das linguagens históricas (a linguagem ideal); c) a qualificação da filosofia como auxiliar no esclarecimento de problemas e enunciados das ciências empíricas - o que a tornaria parte da ciência e não uma disciplina independente; d) a recusa à metafísica - apenas as proposições empíricas e as proposições analíticas, da lógica e da matemática, deveriam ser admitidas. 
Pode-se sintetizar os referidos propósitos em um: separar aquilo que pode ser considerado como ciência daquilo que não pode. Apenas as proposições referentes a fatos (empíricas) ou a relações lógicas entre conceitos (analíticas) possuem significado. Estas em virtude de poder ter seu valor de verdade determinado pela inspeção do significado das palavras (ou símbolos) que as constituem, aquelas porque podem ser verificadas pela experiência. O propósito da filosofia para os neopositivistas, portanto, "é elucidar as proposições da ciência empírica por meio da análise lógica do significado" (GRAYLING, 2002, p. 79-80). Ou seja, a filosofia, a lógica e a matemática são partes não autônomas da ciência. A metafísica, porém, tenta dar significado a termos que não possuem denotação na experiência, sendo assim, suas proposições podem expressar um sentimento, por exemplo, mas não têm sentido, pois não descrevem um estado de coisas (CARNAP; HAHN; NEURATH, 1986, p. 10).

O programa de pesquisa neopositivista discorre ainda sobre as tradições em que se encontra, ${ }^{2}$ vez que o movimento não se caracteriza tanto por teses próprias, mas por sua orientação de pesquisa. Percebe-se o interesse pela logística, da qual adotaram o método de análise lógica, ${ }^{3}$ que consiste em nada mais que a aplicação da linguagem simbólica desenvolvida pela primeira fase da filosofia analítica - o cálculo proposicional - às proposições das ciências naturais com o intuito de purificá-las de qualquer traço de metafísica.

2 Apresenta uma lista de filósofos e cientistas, discriminando-os pelas áreas de conhecimento: "1. Positivismo e Empirismo: Hume, Iluminismo, Comte, Mill, Richard Avenarius, Mach. 2. Fundamentos, Objetivos e Métodos da Ciência Empírica (hipóteses em física, geometria, etc.): Helmholtz, Riemann, Mach, Poincaré, Enriques, Duhem, Boltzmann, Einstein. 3. Logística e sua aplicação à realidade: Leibniz, Peano, Frege, Schroder, Russell, Whitehead, Wittgenstein. 4. Axiomática: Pasch, Peano, Vailati, Pieri, Hilbert. 5. Eudemonismo e sociologia positivista: Epicuro, Hume, Bentham, Mill, Comte, Feuerbach, Marx, Spencer, Müller-Lyer, Popper-Lynkeus, Carl Menger (pai)" (Cf. CARNAP; HAHN; NEURATH, 1986, p. 8.)

3 Pontes de Miranda refere-se a esse método, ao tratar sobre a ciência jurídica, dizendo que "a subordinação dela [a ciência jurídica] à metodologia que resultou da lógica contemporânea, inclusive no que concerne à estrutura dos sistemas, é o último degrau a que se atingiu" (Cf. PONTES DE MIRANDA, 2012, p. 19.) 
Para os representantes do positivismo lógico, "o esclarecimento dos problemas filosóficos tradicionais conduz a que eles sejam parcialmente desmascarados como pseudoproblemas" (CARNAP; HAHN; NEURATH, 1986, p. 10) pela submissão das proposições da linguagem à análise lógica. É exatamente esse o posicionamento adotado por Ludwig Wittgenstein (1968, p. 53) constante no Tractatus Logico-philosophicus - obra que os membros do Círculo estudaram cuidadosamente nos encontros ocorridos entre 1925 e 1926. Inclusive, com base nos postulados de Wittgenstein, ${ }^{4}$ Moritz Schlick elaborou o princípio de verificação, segundo o qual as proposições que possuem sentido são aquelas que determinam estados de coisas possíveis e, portanto, podem ser empiricamente verificadas (GRAYLING, 2002).

É evidente a presença do positivismo lógico no trabalho de Pontes de Miranda, podendo ser notada tanto na primeira quanto na segunda fase de seu trabalho. Contudo, apenas em O Problema Fundamental do Conhecimento pode-se dizer que fica ainda mais nítida a influência desse movimento em seu pensamento, quando ele afirma que a "vinda de Russel, Wittgenstein, Reichanbach, Rudolf Carnap e outros, após Mach, completa, sociologicamente, a linha que esboçava para a renovação da Filosofia no sentido de não mais se sobrepor à ciência" (1999, p. 229). Nota-se ainda, nessa declaração, sua concordância com o papel da filosofia de auxiliar das ciências naturais.

O memorável jurista também pactuava do entendimento de que a possibilidade do conhecimento está relacionada à verdade ou falsidade das proposições verificáveis pela experiência, tendo mantido essa convicção durante toda a sua carreira, conforme se constata nos Comentários a Constituição de 1967, pela asserção: "a Ciência é a livre disponibilidade do espírito, mas tem peneira fina, que é a da verificabilidade" (1970, p. 29).

Entre os quais os seguintes: "a proposição é a descrição de um estado de coisas; compreender uma proposição é saber o que ocorre, caso ela for verdadeira" (Cf. WITTGENSTEIN, 1968, $\S \S 4.023,4.024$.) 


\section{O SISTEMA DOGMÁTICO PONTEANO}

Neste tópico, o escopo é mostrar como a noção de incidência infalível da norma jurídica pretende alcançar uma verdade absoluta sobre os fatos. Para isso, será necessário indicar como as duas fases da obra ponteana estão ligadas.

Na concepção de Pontes de Miranda (2012, p. 14-18), o sistema jurídico é composto por regras jurídicas, e estas, por sua vez, por conceitos jurídicos, que devem ser precisados historicamente. O elemento histórico "é mais exterior, social, do que interior e psicológico", não havendo lugar para se indagar sobre a vontade do legislador ou da lei. Sob esse prisma, deve-se analisar aquilo que o decurso do tempo provocou nas instituições jurídicas, observar as formas que o direito foi assumindo. Só assim se poderá “datar o que apareceu no momento próprio e o que apareceu em momento impróprio". Isso remete ao método faseológico ou sociológico científico, que, segundo o próprio estudioso, foi utilizado em todos os seus trabalhos, tanto de dogmática quanto de sociologia. Nesse método, parte-se da premissa de que todos os ramos do saber, inclusive o Direito, progridem de acordo com a lei evolutiva das três fases cíclicas da mentalidade, "todos começam pela intuição, passam pelo dedutivismo e chegam à positividade" (1983, p. 147). É assim que se torna possível falar em "regressões" ou "prematuridades legislativas" (2012, p. 18).

Em Introdução à Política Científica, de sua primeira fase, Pontes de Miranda (1983, p. 185-186) dispõe sobre o critério da objetividade nas pesquisas jurídicas como forma de desvencilhar-se do arbítrio da vontade humana na consecução das funções estatais. Dentro desses moldes, o Poder Legislativo teria a atribuição de organizar a livre revelação do direito. A elaboração das leis se faria "segundo os dados e materiais de observação, de estatística, etc., e não segundo a opinião, o pendor ou o credo político dos legisladores", que deveriam, portanto, descobrir a regra jurídica. A adoção desses procedimentos na produção da legislação é, sem dúvida, na doutrina ponteana, típica de um círculo 
social ou ramo do saber que atingiu a fase positiva ou indutivista da lei evolutiva das três fases.

No Tratado de Direito Privado, no mesmo sentido, assevera que "o direito, ainda o direito não-costumeiro, é obra de milhares e milhares de inteligências. Daí ter-se de colher, aqui e ali, a verdade" (2012, p. 21). Isto evidencia que, em sua dogmática jurídica, ainda persiste o entendimento, constante na fase positivo-sociológica, de que a regra jurídica escrita deve ser extraída da realidade social de forma objetiva. $\mathrm{O}$ Poder Legislativo deve organizar a livre revelação do direito por meio de trabalhos técnicos de observação e quantificação dos fenômenos sociais para capturar, pelo método científico, a regra jurídica escrita, que, dessa forma, seria conseguida sociologicamente. Por conseguinte, toda análise interna que se faça do sistema jurídico estaria alicerçada indiretamente, de acordo com a concepção cientificista em comento, na realidade social.

É dessa maneira que a incidência infalível de Pontes de Miranda reflete o caráter dogmático de toda sua obra, pois as normas jurídicas correspondem a "fatos da vida" (2012, p. 13), existe a necessidade de um nexo de causalidade entre regras jurídicas e fatos, onde as primeiras precisam refletir situações reais da vida (estados de coisas possíveis), caso contrário não passariam de ato de vontade arbitrário do legislador, que nada possuiria de científico. A ideia de significado, de verdade, típica do positivismo lógico, depende completamente de uma exata correspondência entre um enunciado linguístico e o fato da realidade que ele representa. De outro modo, não há ciência.

\section{WitTGenstein E A COMPLEXIDADE DA LINGUAGEM}

Depois de cerca de dez anos longe da filosofia, em 1929 Wittgenstein retorna a Cambridge e ingressa em um período intenso de atividade intelectual. A retomada dos trabalhos filosóficos, pelo que se sabe, deve-se ao período em que manteve contato com membros do Círculo de Viena. As ideias destes acabaram influenciando-o no sentido de afastar-se cada vez mais das teses que defendeu no Tractatus. A princípio, ele 
preservou suas visões iniciais, deu-lhes uma interpretação positivista por um curto período, e por fim, por volta de 1930, passou a considerá-las equivocadas em vários aspectos importantes (GRAYLING, 2002).

No prefácio das Investigações Filosóficas, principal obra de sua segunda fase, Wittgenstein (1999, p. 26) reconhece os "graves erros" presentes no Tractatus, acrescentando que para se compreender realmente seus novos pensamentos seria necessário confrontá-los com o seu "velho modo de pensar". Nesse sentido, a refutação de sua filosofia anterior serviu como impulso para a nova, mas seu propósito continua o mesmo: mostrar que os problemas da filosofia surgem de uma má compreensão do funcionamento da linguagem (SCHMITZ, 2004).

No Tractatus, a linguagem é explicada como tendo uma essência, uma única lógica subjacente ancorada na relação afiguradora que se estabelece por meio da vinculação entre nomes e objetos ${ }^{5}$ (GRAYLING, 2002). Nas Investigações, Wittgenstein (1999, § 23) quer mostrar que não há apenas uma lógica na linguagem, mas muitas. O significado de uma expressão é seu uso nas diversas práticas que compõem a linguagem, que não é completa e autônoma, devendo ser investigada em conexão com os comportamentos humanos, pois "o falar da linguagem é uma parte de uma atividade ou de uma forma de vida".

Para conseguir seus objetivos Wittgenstein (1999, §§ 38, 90, 109$111,116,124,126)$ adota um método que implica não construir teorias, consistindo em abandonar pretensões de elucidação e dedicar-se somente à descrição. Nada de hipotético poderia permear suas considerações. Trata-se de uma investigação gramatical - não no sentido, geralmente utilizado, de regras atinentes à correção de uma língua específica, mas no de identificar a lógica da linguagem em diferentes contextos. A ideia é apenas organizar aquilo que já se sabe sobre a linguagem, mas que pode ser difícil de enxergar devido a "ilusões gramaticais". É preciso reconduzir as palavras "do seu emprego metafísico para seu emprego cotidiano", pois a filosofia não pode fundamentar o uso efetivo da linguagem, apenas descrevê-lo.

Nas palavras do primeiro Wittgenstein, "o nome denota o objeto. O objeto é sua denotação” (Cf. WITTGENSTEIN, 1968, § 3.203.) 
Dessa forma, para dar início à descrição do funcionamento da linguagem, partindo da oposição à sua antiga concepção, cita como exemplo, ao invés do Tractatus, uma passagem das Confissões, de Santo Agostinho, para demonstrar que a visão representacionalista da linguagem é tão antiga quanto difundida. ${ }^{6}$

Assim, pois, quando chamavam alguma coisa pelo nome, eu a retinha na memória e, se ao pronunciar de novo a tal palavra, moviam o corpo na direção do objeto, eu entendia e notava que aquele objeto era o denominado com a palavra que pronunciavam, porque assim o chamavam quando o desejavam mostrar. Que esta fosse sua intenção, era-me revelado pelos movimentos do corpo, que são como uma linguagem universal, feita com a expressão do rosto, a atitude dos membros e o tom da voz (2002, p. 37-38).

Para Wittgenstein $(1999, \S \S 1,92,97,99,106,126)$, Agostinho expõe determinada compreensão da "essência da linguagem humana", em que toda palavra tem um significado, que é o objeto por ela denominado. Há uma correlação significativa entre a palavra e o objeto. E as proposições são ligações entre objetos. Todavia, essa maneira de enxergar a linguagem pode levar a equívocos, deixando a entender que se deve sempre buscar a maior clareza possível do significado das expressões, como se toda proposição devesse ter um sentido determinado. Ademais, faz que se procure relações lógicas gerais que tentem revelar as "últimas sutilezas" que se encontram "abaixo da superfície”. Mas a essência está oculta, não podemos desvendá-la com os meios que possuímos.

Wittgenstein $(1999, \S \S 7,23,27,654,655)$ emprega então o termo "jogos de linguagem" para referir-se ao conjunto formado pela linguagem e as atividades com as quais está interligada. Existem infinitas formas de utilização dos signos, palavras e frases que constituem a lingua-

6 Além de Agostinho, a mesma visão é partilhada por Sócrates e Bertrand Russell mencionando apenas os exemplos que o próprio Wittgenstein coloca nas Investigações. (Cf. WITTGENSTEIN, 1999, § 1, 46.) 
gem, e surgem novas todo tempo. A multiplicidade de situações em que se faz uso da linguagem - comandar, descrever, contar histórias, pedir, agradecer, saudar, orar, cantar - são cada uma delas diferentes jogos de linguagem. A questão é perceber que se está inserido nesses jogos e não tentar elucidá-los.

Mas o que faz que a linguagem seja um conjunto de jogos de linguagem? O que estes têm em comum? Wittgenstein (1999, §§ 65-67) diz que "não há uma única coisa comum a esses fenômenos", mas todos estão aparentados uns com os outros de muitas formas diferentes. Para explicar esse ponto, faz uma comparação aos jogos em geral (de tabuleiro, de cartas, de bola etc.) e diz que nestes não há algo que seja comum a todos, o que se vê são parentescos, uma complicada rede de semelhanças, como as que ocorrem entre membros de uma família: “estatura, traços fisionômicos, cor dos olhos, o andar, o temperamento, etc." Por isso, utiliza-se da expressão "semelhanças de família", querendo destacar que a linguagem não possui uma essência, uma lógica única. Ao contrário, os jogos que a constituem possuem diversas funcionalidades, que podem ser mais ou menos análogas entre si.

Wittgenstein $(1999, \S \S 2,3,7,30-33,43)$ chama a maneira como Agostinho entende a linguagem de elucidação ou definição ostensiva, considerando-a como nada mais que uma linguagem primitiva - ou um tipo de jogo de linguagem. "A significação de uma palavra é seu uso na linguagem", e a definição ostensiva pode esclarecer o significado de uma palavra, em determinado contexto, desde que o aprendiz domine as regras desse jogo de linguagem específico. Quando uma pessoa adulta, por exemplo, chega a um país estrangeiro do qual não conhece a língua, pode compreender as explicações que os nativos the dão por meio de elucidações ostensivas. Contudo, Agostinho fala do aprendizado da linguagem humana por uma criança como se ela já tivesse uma linguagem própria, "como se a criança já pudesse pensar, e apenas não pudesse falar. E 'pensar' significaria aqui qualquer coisa como: falar consigo mesmo".

Como se pode saber quando alguém aponta para alguma coisa e profere sons em uma língua estranha que está se referindo ao nome desse objeto, e não à forma, à cor, à quantidade? Provavelmente, por in- 
termédio dos gestos que faz, do olhar, das expressões faciais. Portanto, não é necessário apenas saber para o que se aponta, e mesmo que fosse só isso, uma criança precisa aos poucos aprender essas regras para que possa dominar a elucidação ostensiva como jogo de linguagem (WITTGENSTEIN, 1999, §§ 33-35).

Wittgenstein $(1999, \S \S 150-155,199)$ mostra que a compreensão do significado das expressões em qualquer jogo de linguagem depende da observância das regras para seu uso estabelecidas pelos costumes de uma comunidade. "Compreender uma linguagem significa dominar uma técnica", não se trata de um "estado" ou "processo anímico", como algo pairando na mente, e difere de ter uma experiência (tristeza, excitação, dor). Apesar de haver processos anímicos concomitantes característicos da compreensão, não é nisso que ela consiste.

A compreensão, ao invés de um processo interno e privado, está relacionada às instituições humanas (hábitos, costumes), visto que nesses contextos as pessoas são treinadas a reagir a certos estímulos de maneira determinada, ou seja, é a constância dos usos acordados pela comunidade que indicam a existência de regras, e a capacidade de reconhecer e aplicá-las equivale a compreendê-las. Com as expressões da linguagem ocorre o mesmo, é preciso perceber, dentro de cada jogo de linguagem, quando cabe o emprego das palavras. Logo, compreender é algo externo, uma técnica de domínio público, não um processo anímico e pessoal (WITTGENSTEIN, 1999, §§ 198, 199).

Passar por alguma experiência, por sua vez, é um estado ou processo anímico, e a sua manifestação, quando expressa por linguagem, funciona como substituto à forma de "expressão originária e natural da sensação" - como, no caso da dor, gritar, gemer, encolher-se. Assim, dizer que se está com dor é parte do comportamento relativo a essa sensação. A linguagem não fica "entre a manifestação da dor e a dor", ela é a dor expressa em palavras. O significado de expressões que se referem a conceitos psicológicos segue as mesmas regras de uso dependentes de critérios públicos, visto que não se pode adivinhar como uma palavra funciona, é necessário perceber seu emprego e aprendê-lo (WITTGENSTEIN, 1999, §§ 151, 244, 256, 305, 340, 343). Segundo 
Grayling (2002, p. 119), para Wittgenstein, o domínio da linguagem verbal "introduz níveis de riqueza e sutileza inacessíveis para criaturas que não a usam [...] a diferença entre comportamento verbal e outro comportamento é de grau, não de tipo".

Decorrente da noção de significado adotada por Wittgenstein (1999, $\S \S 19,23,241,242$; p.165 - parte II), existe a questão da posição em que se coloca a ideia de verdade. Ciente disto, confirmando as impressões a respeito, afirmou que certo e errado "é o que os homens dizem" enquanto usam a linguagem na qual estão concordes - não no sentido de uma concordância de opiniões, mas de formas de vida. $\mathrm{O}$ significado das expressões linguísticas existe apenas em função da natureza do próprio animal humano e de suas perspectivas compartilhadas, que dão sentido às definições e juízos acordados. Portanto, forma de vida é a estrutura de referência em que se aprende a dominar, por meio de treinamento, a linguagem de uma comunidade, assim como, a perspectiva e as práticas com as quais se encontra vinculada. A linguagem está enraizada nas formas de vida.

Observa-se do que foi colocado que a argumentação do segundo Wittgenstein pretende descrever a linguagem em seu funcionamento cotidiano, procurando mostrar aquilo que já é conhecido e que pode ser evidenciado por ordenação, por intermédio de uma consideração "gramatical", resolvendo os equívocos relacionados ao uso das palavras e enfatizando o seu aspecto comunicacional.

\section{A IMPOSSIBILIDADE DE INCIDÊNCIA INFALÍVEL DA NORMA JURÍ- DICA}

A ideia de uma incidência infalivel, como apresentada na teoria do fato jurídico, apoia-se em uma visão cientificista de que as regras jurídicas figuram fatos da vida de maneira precisa (especular), numa autêntica reprodução da pressuposição neopositivista de que o mundo e a linguagem possuem a mesma forma lógica (isomorfismo), permitindo a figuração de estados de coisas pelas proposições da linguagem. A infalibilidade da incidência seria, dessa maneira, uma consequência da 
coexistência das seguintes premissas: a) uma proposição com sentido descrevendo um estado de coisas possível de ocorrer no mundo - regra jurídica; b) o estado de coisas descrito pela regra jurídica (proposição significativa). O momento da aplicação da norma jurídica corresponde à verificação (princípio de verificação) da existência do estado de coisas previsto no enunciado normativo, mas a existência em si (incidência) independe de interpretação/aplicação (verificação).

A teoria ponteana, pelo que se pode perceber, é inteiramente estruturada na noção neopositivista de linguagem. E, realmente, uma incidência das regras jurídicas ocorrendo anteriormente à própria interpretação/aplicação apenas é razoável de se pensar na forma como o próprio Pontes de Miranda o fez: por meio de uma fundamentação que tente demonstrar a univocidade das expressões linguísticas.

Contudo, o segundo Wittgenstein atacou muitos dos fundamentos de sua primeira fase, demonstrando, entre outras coisas, que a linguagem é muito mais complexa do que ele mesmo havia suposto, não possuindo uma única lógica, mas muitas, e cada uma delas deve ser encontrada por meio da análise gramatical (lógica linguística) dos variados jogos de linguagem que a constituem. Não há como predeterminar o significado das expressões fora dos contextos peculiares aos quais Wittgenstein chamou de formas de vida. Há a necessidade de inserção em um jogo de linguagem específico para que se possa compreender o significado das palavras empregadas no discurso. Deve-se identificar o sentido do interpretado e da interpretação, pois esta não serve de apoio àquele, ambos se encontram indeterminados enquanto não há uma referência para uso das expressões. "As interpretações não determinam sozinhas a significação” (WITTGENSTEIN, 1999, § 198). Portanto, uma doutrina do direito de caráter dogmático e adepta da teoria figurativa, desenvolvida pelo primeiro Wittgenstein no Tractatus Logico-philosophicus, não suporta a complexidade da linguagem e, por conseguinte, do fenômeno jurídico.

Quando trata da relação entre interpretação e isomorfia, Eros Grau (2009, p. 74-75) aduz que nas poucas vezes em que esta ocorre, ainda assim não é possível considerá-la in abstracto, "o mesmo texto é claro 
ou dúbio segundo os contextos concretos do seu uso; a clareza (isomorfia), destarte, é noção pragmática, comprometida com alguns caracteres semânticos da linguagem jurídica".

Ademais, mesmo que fosse possível abstrair os equívocos relativos à má compreensão do funcionamento da linguagem presentes na teoria ponteana, existem algumas incoerências intrínsecas à sua própria sistemática que tornam inconcebível uma incidência infalível.

Segundo Pontes de Miranda (2012, p. 14-19), os sistemas jurídicos são constituídos por regras jurídicas, que, por sua vez, formulam-se por intermédio dos conceitos jurídicos. Estes devem ser fixados e precisados historicamente. A importância dos "estudos históricos" está em se conhecer as instituições jurídicas desde seus "nascedouros", distinguindo-as de outros processos sociais de adaptação, e percebendo-se "as formas que o direito foi assumindo" com o passar do tempo. É possível também, por meio desse método (etnológico, histórico-comparativo, faseológico ou sociológico científico), situar na evolução jurídica "cada enunciado do sistema lógico".

Contudo, o estudo das formas que as instituições jurídicas adquiriram com o transcurso do tempo promove a atualização do direito, com isso os conceitos jurídicos seriam mutáveis e a incidência também, então como poderia ser infalível? Mesmo que se argumentasse que a determinação do conceito deveria alcançar o momento em que o suporte fático se realizou, como se poderia precisar em que estágio de "evolução jurídica" a instituição se encontraria exatamente em cada caso concreto? E se tivessem que ser determinados em cada caso, como a incidência poderia continuar infalível?

Além disso, toda atividade de interpretação tem, para Pontes de Miranda, o propósito de aplicar a norma jurídica, tentando descobrir se houve incidência. A aplicação deve declarar, ou não, a incidência. Entretanto, por meio de quais parâmetros pode-se alegar que a aplicação é, ou não, correta, correspondendo à incidência?

A incidência, caso tenha ocorrido, é equiparada à verdade absoluta. E, visto que, na concepção ponteana, "as regras jurídicas são de conteúdo determinado, e não se poderia deixar ao arbítrio de alguém a 
incidência delas, ou não" (2012, p. 70-71), os estudos históricos efetuados para precisar os conceitos jurídicos fazem parte do processo de interpretação/aplicação das normas jurídicas. Entretanto, como esses estudos, que também seriam feitos por homens, poderiam alcançar tamanha exatidão? Segundo Pontes de Miranda (2012, p. 19), por meio da subordinação da linguagem à "metodologia que resultou da lógica contemporânea" - o método de análise lógica. Volta-se ao início - à ideia de que toda a teoria do fato jurídico é construída sobre a possibilidade do representacionalismo da linguagem.

É difícil livrar-se dessa visão representacionalista, que enxerga a verdade como correspondência entre linguagem e mundo, já que domina o senso comum contemporâneo. Para o pragmatismo, todavia, não há qualquer critério para a verdade além da justificação. E, quando se fala em justificação, deve-se perguntar: justificar o quê? Para quem? Em qual situação? Não existem verdades absolutas, pois não há algo que possa ser justificado de maneira definitiva. Richard Rorty (2005, p. IX-X) afirma que "ninguém deveria nem mesmo tentar especificar a natureza da verdade", principalmente os pragmatistas, pois o verdadeiro é indefinível, "nenhuma teoria sobre a natureza da verdade é possível. Só há algo a dizer a respeito do relativo". Mas isso não quer dizer que se deva incorrer em um relativismo exagerado ou aderir ao ceticismo.

O pragmatismo situa-se entre o dogmatismo e o relativismo, e sua proposta alerta que "nós não temos nenhuma compreensão da verdade que seja distinta da nossa compreensão da tradução" (RORTY, 2005, p. X-XI). É a perspectiva humana que interessa. A verdade não é o objetivo da investigação. Um objetivo é algo do qual se pode dizer que se está mais distante/próximo. Não há como dizer isso sobre a verdade. $\mathrm{O}$ importante é buscar justificação, pois somente assim pode-se encontrar soluções úteis para as necessidades e interesses humanos.

\section{CONSIDERaÇões FINAIS}

Ludwig Wittgenstein influenciou explicitamente o neopositivismo de Pontes de Miranda, que faz citações e menções ${ }^{7}$ ao trabalho daque-

7 Cf. Pontes de Miranda, 2012, p. 82 e 1999, p. 229. 
le. Além disso, o movimento do Círculo de Viena como um todo foi fortemente marcado pela teoria figurativa do significado, apresentada no Tractatus Logico-philosophicus. O próprio princípio de verificação, segundo o qual um enunciado linguístico apenas seria verdadeiro se representasse um estado de coisas existente no mundo, é nada mais que um método, e se sustenta totalmente nos conceitos formulados pelo primeiro Wittgenstein, conforme foi demonstrado. Isso leva a concluir que a possibilidade mesma de ter existido o movimento neopositivista deve-se, principalmente, à primeira fase de Wittgenstein.

Na teoria de Pontes de Miranda, para se constatar a ocorrência de um fato jurídico, o intérprete deve tentar determinar se o suporte fático concreto corresponde ao que está previsto na norma. A interpretação/ aplicação busca apenas constatar a isomorfia entre a norma e o fato, pouco importam questões atinentes à moral, valores ou justiça. A teoria do fato jurídico é o reflexo mais claro da tradição neopositivista para o Direito.

Todavia, como ficou esclarecido, o segundo Wittgenstein, ao fundar a pragmática analítica, desconstruiu sua antiga teoria, elaborou um novo método de análise pautado pela observação da lógica da linguagem nos seus diversos contextos, e chegou à conclusão de que o significado das expressões linguísticas apenas pode ser encontrado no seu uso, que está sempre associado às práticas humanas. Não há, por conseguinte, a possibilidade de predeterminar o significado da linguagem. Para o pragmatismo o conhecimento é contextual, e a verdade é equivalente à justificação.

Quando Pontes de Miranda desenvolveu a teoria do fato jurídico, suas ideias eram contemporâneas. No entanto, após todo o avanço conquistado pela filosofia analítico-pragmática e pela hermenêutica filosófica ${ }^{8}$ na teoria do conhecimento, continua-se, injustificadamente, a aceitar a monossemia da linguagem na teoria geral do Direito. Há

Escola filosófica que, apesar da origem diametralmente diversa, convergiu para o mesmo entendimento que o pragmatismo sobre a natureza da linguagem e do conhecimento. 
muito a filosofia deixou o neopositivismo no passado, como uma parte da evolução epistemológica, que deixou sua contribuição, mas está superada. O Direito precisa fazer o mesmo. É necessário abandonar definitivamente visões reducionistas do fenômeno jurídico.

\section{REFERÊNCIAS}

AGOSTINHO, S. Confissões. Tradução: Alex Marins. São Paulo: Martin Claret, 2002.

ANTISERI, D.; REALE, G. História da filosofia: de Nietzsche à escola de Frankfurt. Tradução: Ivo Storniolo, v. 6. São Paulo: Paulus, 2006a.

. História da filosofia: de Freud à atualidade. Tradução: Ivo Storniolo, v. 7. São Paulo: Paulus, 2006b.

BOBBIO, N. Teoria da norma jurídica. Tradução: Fernando Pavan Baptista; Ariani Bueno Sudatti, 4. ed. Bauru: Edipro, 2008.

CARNAP, R.; HAHN, H.; NEURATH, O. A concepção científica do mundo: O Círculo de Viena. Tradução: Fernando Pio de Almeida Fleck. Cadernos de História e Filosofia da Ciência. Campinas, a. 7, n. 10, p. 5-20, 1986.

CASTRO JR. T. A pragmática das nulidades e a teoria do ato jurídico inexistente: reflexões sobre metáforas e paradoxos da dogmática privatista. São Paulo: Noeses, 2009.

GRAU, E. R. Ensaio e discurso sobre a interpretação/aplicação do direito, 5. ed. São Paulo: Malheiros, 2009.

GRAYLING, A. C. Wittgenstein. Tradução: Milton Camargo Mota. São Paulo: Edições Loyola, 2002.

KRELL, A. J. A relevância da teoria do fato jurídico no âmbito do moderno direito constitucional e administrativo. In: DIDIER JR., F.; EHRHARDT JR., M. (Org.). Revisitando a teoria do fato jurídico: homenagem a Marcos Bernardes de Mello. São Paulo: Saraiva, 2010.

MELLO, M. B. Teoria do fato jurídico: plano da existência, 16. ed. São Paulo: Saraiva, 2010. 
PONTES DE MIRANDA, F. C. Comentários à Constituição Federal de 1967 (com a Emenda n. 1, de 1969). t. I. São Paulo: Revista dos Tribunais, 1970.

. Introdução à política científica. Rio de Janeiro: Forense, 1983.

1999.

. O problema fundamental do conhecimento. Campinas: Bookseller, 2012.

. Tratado de direito privado. t. I. São Paulo: Revista dos Tribunais,

REALE, M. Filosofia do direito, 20. ed. São Paulo: Saraiva, 2002.

RORTY, R. Verdade e progresso. Tradução: Denise R. Sales. Barueri: Manole, 2005.

SCHMITZ, F. Wittgenstein. Tradução: José Oscar de Almeida Marques. São Paulo: Estação Liberdade, 2004.

WITTGENSTEIN, L. Investigações filosóficas. Tradução: José Carlos Bruni. São Paulo: Nova Cultural, 1999.

. Tractatus logico-philosophicus. Tradução: José Arthur Giannotti. São Paulo: Companhia Editora Nacional, 1968.

\section{SOBRE O AUTOR}

Antonio Wilker dos Santos

Especialização em andamento em Direito Constitucional pela Universidade Candido Mendes, UCAM, Timóteo, MG, Brasil. Especialização em andamento em Análise de Discurso Político e Jurídico pela Faculdade Unyleya, UNYLEYA, Brasília, DF, Brasil. Graduação em Direito pela Universidade Federal de Alagoas, UFAL, Maceió, AL, Brasil.

CV: http://lattes.cnpq.br/2498072537001985

E-mail: wilker04@outlook.com

Submetido em: 10-6-2017

Aceito em: 24-11-2017 